\title{
Use of Renewable Energies in Sustainable Facilities for Rural Housing Module
}

\author{
André Ccorisapra ${ }^{1}$, Jonathan Mora ${ }^{1}$, César Lozano ${ }^{1, a}$ and Carlos Huerta ${ }^{1}$ \\ ${ }^{1}$ Ingeniería Civil, Universidad Peruana de Ciencias Aplicadas, Lima, Perú
}

\begin{abstract}
Many rural homes, due to their distance to the main population centres, do not have the basic infrastructure, at the level of facilities, required by the needs demanded by its inhabitants. The design of electrical and sanitary installations of a sustainable nature is intended, and its implementation in a rural housing module. For which is based on the treatment of reliable data and existing in each place, determining the supply of renewable resources of greater predominance, such as solar, wind and rainwater. The estimation of global solar energy is determined by the method based on the Bristow-Campbell model; the Weibull distribution is used as a calculation methodology to adjust the frequency distribution of the wind speed in wind energy; likewise, a rainwater collection system is proposed, only for the toilet of the dwelling, which is treated by a biodigester; improving the quality of life of the inhabitants of the rural area through the management of sustainable facilities.
\end{abstract}

\section{Introduction}

Renewable energies offer important opportunities for applications in environments where conventional energy does not arrive or arrives only partially; this is particularly useful in the rural environment, among populations with high levels of marginalization towards these services. The lack of energy in isolated rural communities constitutes a critical situation, since it is usually associated with the absence of telecommunications, education, health services, and frequently, drinking water [1].

In Peru, the absence of pyrometers at meteorological stations reflects the need to apply alternatives to estimate global solar radiation in each place. To estimate solar radiation through a statistical model, some authors have considered the effect that solar rays produce on thermal amplitude. The difference in maximum and minimum temperatures on a given day depends on the relationship between sensible heat and latent heat. Sensitive heat varies according to the incident solar radiation and is responsible for maximum temperatures. During the night, sensible heat is lost into space as long-wave radiation, thus lowering the air temperature to its minimum value, which is normally reached before dawn [2].

The Bristow-Campbell model estimates global solar radiation based on extra-terrestrial solar radiation and temperature difference. Baigorria and other authors [3] concluded that the Bristow-Campbell model was the one that best suits Peru's conditions. This model suggests the estimation of the relative solar transmissivity or irradiation $(\mathrm{H} / \mathrm{H} 0)$ as a function of the difference

\footnotetext{
a Corresponding author: cesar.lozano@upc.edu.pe
}

between the maximum and minimum temperatures $\left({ }^{\circ} \mathrm{C}\right)$ [4].

The thermal transmissivity of a given place is independent of geographical and weather conditions. In the absence of reliable solar radiation data, it is necessary to propose a correlation with available data such as NASA, thereby estimating the transmissivity of the area and thus estimating global solar radiation [5]. The potential of the solar resource in Peru is advantageous for applying renewable solution proposals to take advantage of the solar resource in supplying the electricity demand of a rural dwelling.

Faced with this situation and due to the need in the rural area of Peru, in the present investigation it was proposed to carry out the design of the electrical installation of a typical house to supply the daily consumption of the electrical appliances that the house has. Likewise, the proposal for rainwater collection is developed to be derived only to the toilet of the house where it will be treated by means of a biodigester of 600 L capacity, thereby obtaining a better quality of the hygienic service for the population in the area rural.

\section{Estimation methodology}

The work is carried out supported by analysis methodology with information from different sources such as related research. With this, the treatment and analysis of the existing information is carried out taking as an affected database on the official website of NASA, SENAMHI and the ANA. 
To be able to carry out the treatment and analysis of the available data of the meteorological station, you must first have data on maximum and minimum temperatures of the place under study. Second, global solar radiation data provided by NASA (USA) must be collected, then by means of a least square's adjustment, the monthly thermal transmission constant that best correlation is obtained according to the year under evaluation is obtained. The methodology for estimating global solar radiation is by Bristow-Campbell and that best adapts to the topographic and meteorological conditions of Peru. Thirdly, the configuration of the electricity demand for housing is carried out based on data provided by the latest Population and Housing Census of the INEI [6]. With the amount of electrical demand, the collection system is sized by means of a photovoltaic panel. Finally, the design of the electrical installation of the rural dwelling is obtained by counting the solar system as the electricity supply system.

\subsection{Empirical method to estimate solar radiation}

One of the oldest models is from Angström, which dates to 1924, and is cited by Atlas Solar Energy of Peru [7]; this estimates the daily flux density of global radiation from the following simple linear regression.

$$
\frac{H g}{H e}=a+b\left(\frac{n}{N}\right)
$$

Where $\mathrm{Hg}$ represents global solar radiation, He is extraterrestrial solar radiation, $\mathrm{n}$ corresponds to the hours of real sun and $\mathrm{N}$ is the theoretical duration of the day. In addition, the coefficients "a" and "b" are associated with the type of clouds and the general conditions that determine the turbidity of the atmosphere. Angström, having analysed these coefficients, suggested the values of 0.2 for the "a" coefficient and 0.5 for the "b" coefficient [8].

The coefficients $a+b$ represent the maximum value of the transmissibility of the atmosphere $(\tau)$ while the coefficient a represents the minimum value of $\tau$ [7].

On the other hand, to estimate solar radiation through a statistical model, some authors have considered the effect that solar rays produce on thermal amplitude. The difference between maximum and minimum temperatures on a given day depends on the relationship between sensible heat and latent heat. Sensitive heat varies according to the incident solar radiation and is responsible for maximum temperatures. During the night, sensible heat is lost into space as long-wave radiation, thus lowering the air temperature to its minimum value, which is normally reached before dawn [9].

From this description, Bristow-Campbell, 1984, [7] developed a model to estimate global solar radiation based on extra-terrestrial solar radiation and temperature difference. Within the existing models, Baigorria and other authors [3] concluded that the Bristow-Campbell model was the one that best suited Peruvian scenarios. This model suggests the estimate of the relative solar transmissivity or irradiation based on the difference between the maximum and minimum temperatures $\left(\Delta \mathrm{T},{ }^{\circ}\right.$ C).

$$
\frac{H g}{H e}=a *\left(1-e^{-b(T \max -T \min )^{c}}\right)_{(2)}
$$

Where $\mathrm{Hg}$ represents global solar radiation, He is extraterrestrial solar radiation, Tmax corresponds to the maximum temperature and Tmin is the minimum temperature. In this case, the empirical values $a . b$ and $c$ have a physical meaning; a represents the maximum value of $\tau$ that is characteristic of each study area and also depends on pollution and altitude; $b$ and $c$ determine the effect of the temperature increase on the maximum $\tau$ of the atmosphere.

$$
\begin{aligned}
& c=2.116-0.072(T \max -T \min )+ \\
& 57.574 \div e^{\Phi}
\end{aligned}
$$

$$
b=0.107 * c^{-2.6485}
$$

\subsection{Statistical method for wind resource measurement}

For the purposes of the wind resource it is recommended that the wind speed measurement be taken over a year at 10 minute intervals between measurements, which would lead to more than fifty thousand measurements per year of wind speeds [10].

\subsection{Weibull distribution}

It is a probability function which results in the percentage probability of a certain number of data.

$$
f(v)=\left(\frac{k}{c}\right)\left(\frac{v}{c}\right)^{k-1} \cdot e^{-\left(\frac{V}{c}\right)^{k}}
$$

Where $\mathrm{k}$ is the shape parameter, a dimensionless parameter of the Weibull distribution is treated and $\mathrm{c}$ is the scale parameter, whose dimensions will depend on the variables taken in each case.

There are numerous different methods for calculating the parameters of form $\mathrm{k}$, and scale, $\mathrm{c}$, of the Weibull distribution. In general, they are all equivalent, varying their methodology and complexity.

The $\tilde{V}$ average speed can be calculated from the $\Gamma$ gamma function.

$$
\begin{array}{r}
\tilde{\mathrm{V}}=c * \Gamma\left(1+\frac{1}{k}\right) \\
\left.\frac{\sigma}{(\overline{\mathrm{V}}}\right)^{2}=\left(\frac{\Gamma\left(1+\frac{2}{k}\right)}{\Gamma^{2}\left(1+\frac{1}{k}\right)}\right)-1
\end{array}
$$

Where $\sigma$ is the standard deviation.

The calculation of $\mathrm{k}$ is obtained from the following expression.

$$
k=\left(\frac{\sigma}{\tilde{V}}\right)^{-1.086}
$$

The height influences the wind speed. Near the ground, the speed is low, however, it can be increased 
rapidly when ascending, as shown in Figure 1. Such variation can be represented by the statistical type equation, known as Hellmann's Exponential Law.

$$
V_{h}=V_{10}\left(\frac{h}{10}\right)^{c}
$$

Where:

$\mathrm{Vh}=\mathrm{Wind}$ speed at a height $\mathrm{h}$

$\mathrm{H}=$ height

$\mathrm{V} 10=$ Wind speed at 10 meters high

Alpha $=$ Hellmann Exponent

The Hellmann Exponent varies according to the roughness of the terrain, as shown in Table 1.

Table 1. Values of the Hellmann exponent according to the Roughness of the Terrain [11].

\begin{tabular}{|l|l|}
\hline Flat places with ice or grass & $\alpha=0.08-0.12$ \\
\hline Flat places (sea, coast) & $\alpha=0.14$ \\
\hline Rough terrain & $\alpha=0.13-0.16$ \\
\hline Rustic areas & $\alpha=0.2$ \\
\hline Small town with some trees and shrubs & $\alpha=0.2-0.26$ \\
\hline City areas with high rise buildings & $\alpha=0.25-0.4$ \\
\hline
\end{tabular}
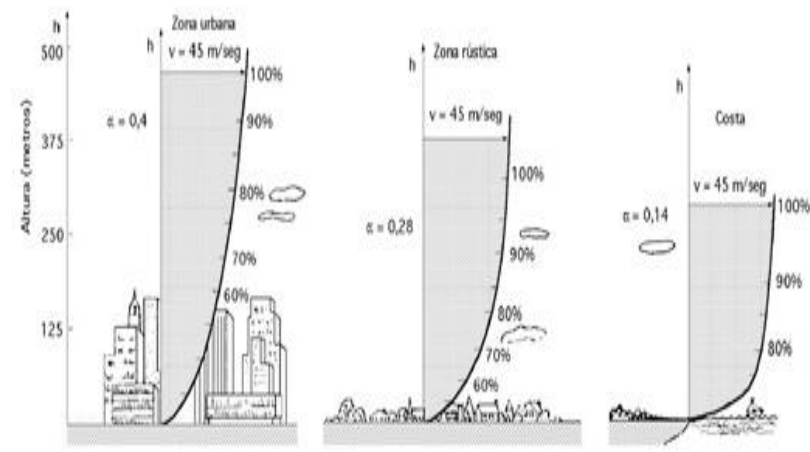

Figure 1. Variation of wind speed with height, according to the Hellmann Exponential Law [11].

\section{Data analysis and results}

In order to carry out the treatment and analysis of the available data, the Sondorillo weather station is chosen as a pilot. The determination of solar, wind and rainwater resources is carried out:

\subsection{Determination of solar resource}

The weather station in Sondorillo does not have a pyrometer to determine the daily global solar radiation directly, therefore, we proceeded to estimate the global solar radiation using the method of Bristow and Campbell, as it is the one that best suits the conditions of the site. The restriction that is perceived is not knowing the transmissivity of the "ab" atmosphere at the place of study, so Bristow-Campbell was used to estimate the global solar radiation of Bristow Campbell with NASA data. The choice of the year to be analysed was based on the highest correlation in this case, as shown in Figure 2

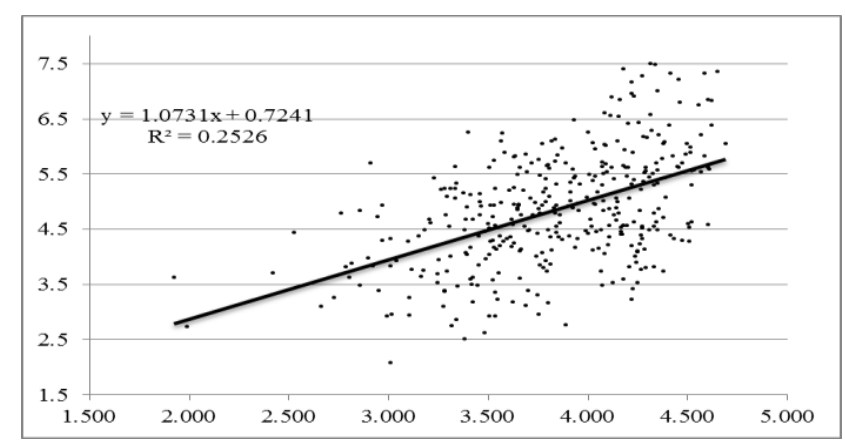

Figure 2. Correlation of NASA's base radiation with the estimation of the BC method for the year 2011. (Source: Own).

Carrying out the base year to be analyzed, the year 2011 was chosen as one of the years with the highest correlation coefficient, as shown in Table 2. With this, the coefficients $a b$ for each month of the year were determined.

Table 2. Pearson coefficients result 2003 - 2015. (Source: Own)

\begin{tabular}{|c|c|}
\hline Year & $\begin{array}{c}\text { Correlation coefficient } \\
(\mathrm{r})\end{array}$ \\
\hline 2003 & 0.1091 \\
\hline 2004 & 0.2789 \\
\hline 2005 & 0.1970 \\
\hline 2006 & 0.3847 \\
\hline 2007 & 0.2216 \\
\hline 2008 & 0.5100 \\
\hline 2009 & 0.3692 \\
\hline 2010 & 0.4910 \\
\hline 2011 & 0.5026 \\
\hline 2012 & 0.4171 \\
\hline 2013 & 0.3526 \\
\hline 2014 & 0.3399 \\
\hline 2015 & 0.3852 \\
\hline
\end{tabular}

Table 3. Result of monthly transmissivity in Sondorillo. (Own source)

\begin{tabular}{|c|c|c|}
\hline Month & $\begin{array}{c}\text { Transmissivity } \\
(\mathrm{Ab})\end{array}$ & $\begin{array}{c}\text { Correlation } \\
\text { coefficient }(\mathrm{r})\end{array}$ \\
\hline January & 0.588 & 0.238 \\
\hline February & 0.573 & 0.648 \\
\hline March & 0.626 & 0.432 \\
\hline April & 0.609 & 0.672 \\
\hline May & 0.684 & 0.499 \\
\hline June & 0.640 & 0.445 \\
\hline July & 0.645 & 0.172 \\
\hline August & 0.729 & 0.366 \\
\hline September & 0.684 & 0.490 \\
\hline October & 0.697 & 0.559 \\
\hline November & 0.672 & 0.647 \\
\hline December & 0.593 & 0.414 \\
\hline Average & $\mathbf{0 . 6 4 5}$ & \multicolumn{1}{|l}{} \\
\cline { 1 - 2 } & \multicolumn{2}{|l}{} \\
\cline { 1 - 2 }
\end{tabular}




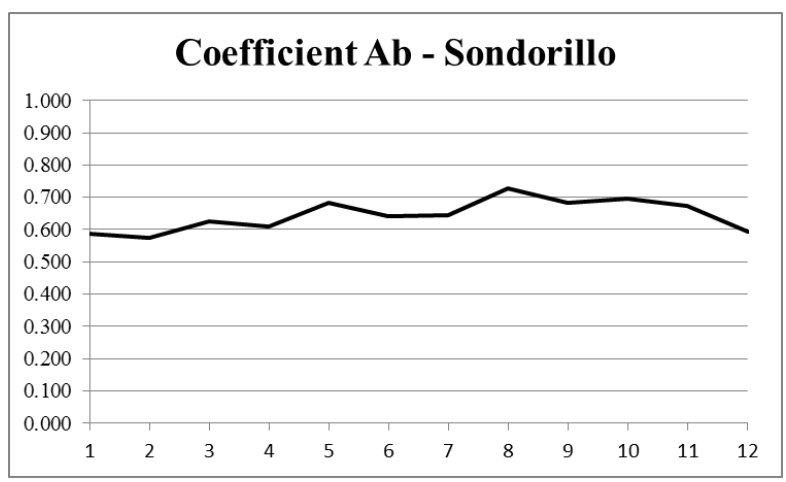

Figure 3. Determination of the transmissivity of the atmosphere in Sondorillo. (Own source).

The value of the transmissivity of the average atmosphere in Sondorillo is 0.645 , as shown in Table 3 and Figure 3, with this value we proceeded to calculate the estimate of the average global solar radiation in Sondorillo with the method of Bristow Campbell, taking into account the average maximum and minimum temperatures calculated in Table 4 . The result gives us a value of $4.98 \mathrm{~kW} / \mathrm{m} 2$, leading to the profitability of the use of the solar resource for electricity generation.

Table 4. Estimation of global solar radiation by the Bristow - Campbell method in Sondorillo. (Own source)

\begin{tabular}{|c|c|c|c|c|c|c|c|c|c|c|c|}
\hline \multicolumn{12}{|c|}{ Proposed Bristow / Campbell model, developed in Excel, to estimate global solar radiation } \\
\hline Average & Sondorillo & & & & & $\varphi$ & Latitude & -5.33979444 & -0.09319699 & $\mathrm{Ab}$ & 0.645 \\
\hline & & & & & & & Altitude & $1917 \mathrm{msnm}$ & & conversion & \\
\hline Julian day & Tmax & Tmin & Latitude (rad) & Eo & $\delta$ & Ws & Heh & $\mathrm{Cb}$ & $\mathrm{Bb}$ & Hs & Hs \\
\hline $\mathrm{dn}$ & ${ }^{\circ} \mathrm{C}$ & ${ }^{\circ} \mathrm{C}$ & $\varphi$ & & $\mathrm{rad}$ & $\mathrm{rad}$ & \multicolumn{2}{|c|}{ MJh m-2dia-1 } & & & \\
\hline 15 & 25.88 & 13.94 & -0.0932 & 1.0319 & -0.3702 & 1.6071 & 38.0757 & 1.5325 & 0.0345 & 19.3181 & 5.3659 \\
\hline 46 & 25.33 & 14.298 & -0.0932 & 1.0232 & -0.2303 & 1.5927 & 38.5718 & 1.5979 & 0.0309 & 18.9439 & 5.2620 \\
\hline 74 & 25.58 & 14.61 & -0.0932 & 1.0097 & -0.0474 & 1.5752 & 38.0050 & 1.6023 & 0.0307 & 18.6177 & 5.1714 \\
\hline 105 & 25.85 & 14.39 & -0.0932 & 0.9923 & 0.1658 & 1.5552 & 35.7284 & 1.5671 & 0.0326 & 17.8383 & 4.9549 \\
\hline 135 & 25.39 & 13.96 & -0.0932 & 0.9774 & 0.3288 & 1.5389 & 32.9020 & 1.5692 & 0.0324 & 16.4094 & 4.5580 \\
\hline 166 & 24.36 & 13.899 & -0.0932 & 0.9683 & 0.4068 & 1.5305 & 31.2016 & 1.6390 & 0.0289 & 14.9367 & 4.1489 \\
\hline 196 & 24.22 & 13.6 & -0.0932 & 0.9679 & 0.3746 & 1.5340 & 31.7866 & 1.6275 & 0.0295 & 15.3327 & 4.2589 \\
\hline 227 & 24.82 & 13.84 & -0.0932 & 0.9762 & 0.2390 & 1.5480 & 34.2345 & 1.6016 & 0.0307 & 16.7776 & 4.6602 \\
\hline 258 & 25.46 & 14.25 & -0.0932 & 0.9912 & 0.0369 & 1.5673 & 36.8663 & 1.5851 & 0.0316 & 18.2353 & 5.0652 \\
\hline 288 & 26.15 & 14.09 & -0.0932 & 1.0080 & -0.1690 & 1.5867 & 38.1216 & 1.5239 & 0.0351 & 19.4125 & 5.3921 \\
\hline 319 & 26.55 & 13.47 & -0.0932 & 1.0232 & -0.3350 & 1.6033 & 38.0294 & 1.4504 & 0.0400 & 19.8841 & 5.5231 \\
\hline \multirow[t]{2}{*}{349} & 26.25 & 13.56 & -0.0932 & 1.0318 & -0.4072 & 1.6111 & 37.7284 & 1.4785 & 0.0380 & 19.5463 & 5.4293 \\
\hline & & & & & & & & & & Average & 4.98 \\
\hline
\end{tabular}

\subsection{Wind resource determination}

For the realization of the wind speed data processing at the Sondorillo station, 2014 was taken as the year of study since it is the year with the greatest amount of data. Also, because the wind speed is not continuous and is very variable during the day, we proceeded to determine the wind speed with the Weibull distribution.

Bias and kurtosis represent the shape and symmetry of the Weibull distribution curve, as shown in Figure 4.

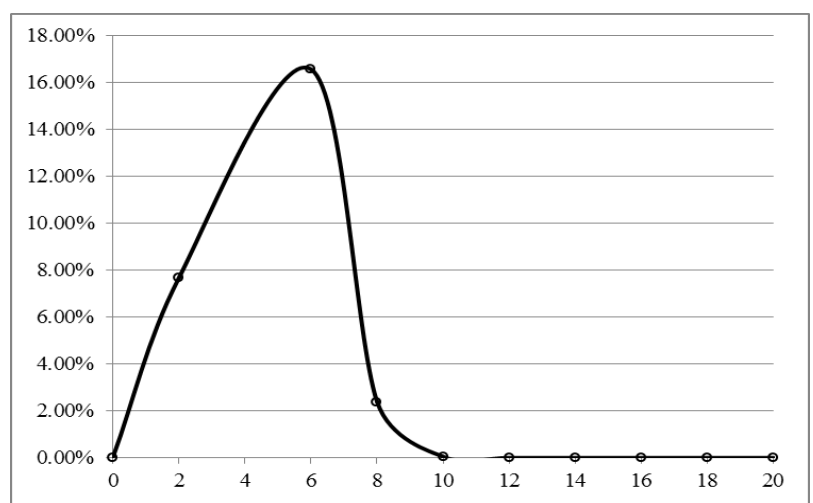

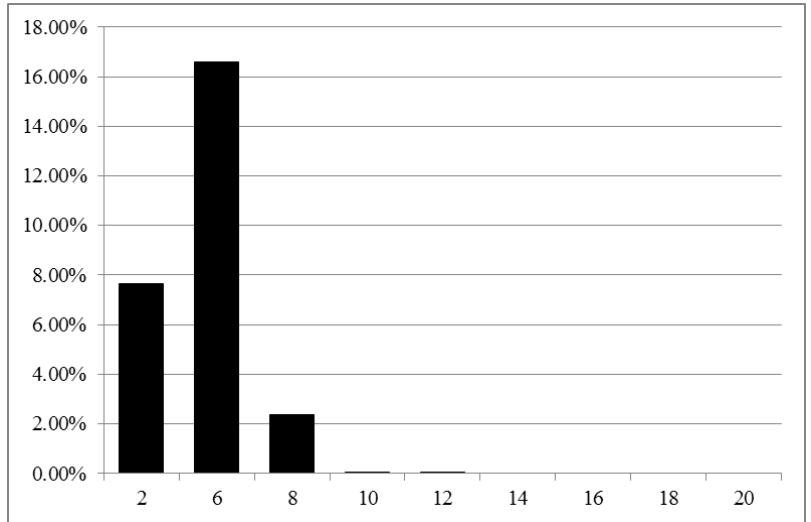

Figure 4. Weibull distribution graph of wind speed in Sondorillo. (Own source).

Obtained the probability of Weibull distribution with the amount of data according to the recorded wind speed, the average speed in Sondorillo was determined, resulting in a value of $6.72 \mathrm{~m} / \mathrm{s}$ at a height of 10 meters of measurement, as shown in Table 5. 
Table 5. Determination of the average speed in Sondorillo. (Own source).

\begin{tabular}{|c|c|c|}
\hline $\begin{array}{c}\text { Wind speed } \\
(\mathrm{m} / \mathrm{s})\end{array}$ & \#Times & Result \\
\hline 2 & 1 & 0.15 \\
\hline 6 & 5 & 4.98 \\
\hline 8 & 8 & 1.53 \\
\hline 10 & 14 & 0.06 \\
\hline 12 & 7 & 0.00 \\
\hline 14 & 7 & 0.00 \\
\hline 16 & 9 & 0.00 \\
\hline 18 & 11 & 0.00 \\
\hline 20 & 4 & 0.00 \\
\hline \multicolumn{2}{|c|}{ Average } & $\mathbf{6 . 7 2}$ \\
\hline
\end{tabular}

Likewise, with the data of the year under study, the predominant wind direction could be visualized by a frequency graph, the East being the predominant direction as shown in Table 6 and Figure 5

Table 6. Determination of the frequency of the wind direction in Sondorillo. (Own source).

\begin{tabular}{|c|c|c|c|}
\cline { 2 - 4 } & \#Times & $\begin{array}{c}\text { Direction of } \\
\text { the wind }\end{array}$ & Frequency \\
\hline \multirow{4}{*}{} & 61 & $\mathrm{E}$ & $92.42 \%$ \\
\hline & 3 & $\mathrm{~N}$ & $4.55 \%$ \\
\hline Total & 2 & $\mathrm{~W}$ & $3.03 \%$ \\
\hline \multicolumn{2}{|c|}{66} & \\
\hline
\end{tabular}

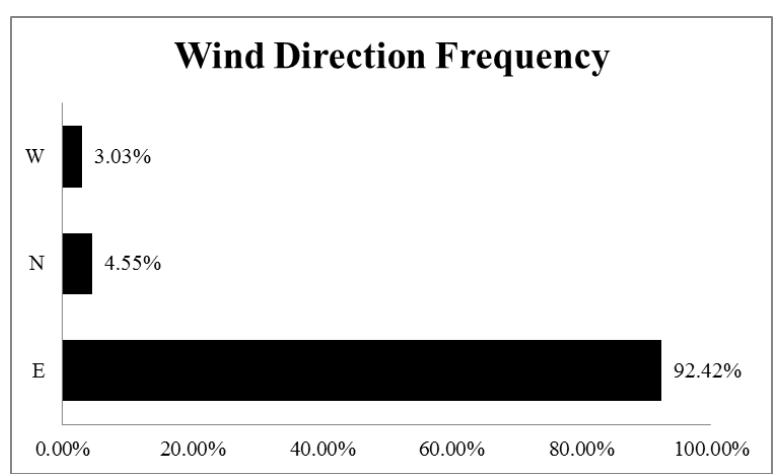

Figure 5. Frequency of wind speed direction in Sondorillo. (Own source).

With the information obtained, the wind speed calculation is carried out at a height of $6 \mathrm{~m}$ because the chosen wind turbine has a height of said characteristic, for this the Hellman Law is used, as observed in Table 7, resulting in an average value of $6.31 \mathrm{~m} / \mathrm{s}$.
Table 7. Average wind speed at a height of $6 \mathrm{~m}$ in Sondorillo. (Own source).

\begin{tabular}{|l|c|c|}
\hline \multicolumn{3}{|c|}{ Wind speed calculation } \\
\hline Speed $\mathrm{V}(\mathrm{h} 2)=$ & $\mathrm{V}(\mathrm{h} 1)^{*} \operatorname{Ln}(\mathrm{h} 2 / \mathrm{a}) / \mathrm{Ln}(\mathrm{h} 1 / \mathrm{a})$ \\
\hline Speed $\mathrm{V}(\mathrm{h} 1)=$ & 6.72 & $\mathrm{~m} / \mathrm{s}$ \\
\hline Height $\mathrm{h} 2=$ & 6 & $\mathrm{~m}$ \\
\hline Height $\mathrm{h} 1=$ & 10 & $\mathrm{~m}$ \\
\hline Roughness class $(\mathrm{Cr})$ & 1 & \\
\hline Roughness coefficient $(\mathrm{a})$ & 0.0024 & \\
\hline Speed $\mathrm{V}(\mathrm{h} 2)$ & $\mathbf{6 . 3 1}$ & $\mathbf{m} / \mathbf{s}$ \\
\hline
\end{tabular}

\subsection{Determination of water resource}

The months were established in which there is a good water supply and, in the months, which this need has to be supplied with the projected storage systems. In this case, based on the average rainfall obtained, it was identified that the periods in which there is more water to collect are the months of January, February, March, April, October, November and December, so 7 months of avenues (rainy season) well marked in the year can be determined. On the other hand, it is observed that in the period from May to September, there are very low rainfall, being the months of July, August and September the most critical, which would not allow an adequate supply in these times that we know as periods of waste Therefore, it is necessary to calculate a storage tank that would allow for the necessary supply that is also being projected in those months of low rainfall.

\subsection{Storage tank calculation}

A table was generated in which the available endowment of rainwater was obtained thanks to the average rainfall obtained from the site. Then, the volume of the storage tank to be used was estimated. On average, the homes in the study area have a covered area of $50 \mathrm{~m} 2$ with an average of 4 people and for our project we are considering a bamboo roof, so the runoff coefficient turns out to be 0.8 , this input data is shown in Table 8 .

Table 8. Input data to determine the water supply (Own source).

\begin{tabular}{|c|c|}
\hline Parameter & Value \\
\hline Coeff. Runoff & 0.8 \\
\hline Roof area (m2) & 50 \\
\hline Number of people benefited & 4 \\
\hline
\end{tabular}


Table 9. Determination of the volume of the storage tank for water reuse in Sondorillo. (Own source).

\begin{tabular}{|c|c|c|c|c|c|c|c|}
\hline \multirow{2}{*}{ Mes } & \multirow{2}{*}{$\begin{array}{c}\text { Average } \\
(\mathrm{mm})\end{array}$} & \multirow{2}{*}{ Days } & \multicolumn{2}{|c|}{ Supply (m3) } & \multicolumn{2}{|c|}{ Demand (m3) } & \multirow{2}{*}{$\begin{array}{c}\text { Difference } \\
(\mathrm{m} 3)\end{array}$} \\
\hline & & & Partial & Accumulated & Partial & Accumulated & \\
\hline January & 59.71 & 31 & 2.39 & 2.39 & 2.01 & 2.01 & 0.38 \\
\hline February & 74.34 & 28 & 2.97 & 5.36 & 1.81 & 3.82 & 1.54 \\
\hline March & 100.21 & 31 & 4.01 & 9.37 & 2.01 & 5.83 & 3.54 \\
\hline April & 72.52 & 30 & 2.90 & 12.27 & 1.94 & 7.77 & 4.50 \\
\hline May & 39.43 & 31 & 1.58 & 13.85 & 2.01 & 9.78 & 4.07 \\
\hline June & 32.20 & 30 & 1.29 & 15.14 & 1.94 & 11.72 & 3.42 \\
\hline July & 27.25 & 31 & 1.09 & 16.23 & 2.01 & 13.73 & 2.50 \\
\hline August & 27.25 & 31 & 1.09 & 17.32 & 2.01 & 15.73 & 1.58 \\
\hline September & 24.02 & 30 & 0.96 & 18.28 & 1.94 & 17.68 & 0.60 \\
\hline October & 49.86 & 31 & 1.99 & 20.27 & 2.01 & 19.68 & 0.59 \\
\hline November & 50.62 & 30 & 2.02 & 22.30 & 1.94 & 21.63 & 0.67 \\
\hline December & 58.43 & 31 & 2.34 & 24.63 & 2.01 & 23.63 & 1.00 \\
\hline
\end{tabular}

Calculation of endowment

$\mathbf{1 6 . 1 9}$ litros/hab-día

Tank volume

4.12

The storage tank will only derive rainwater to the toilet and to the pipe outside the house for irrigation use, so that the amount obtained is only to be used for the discharge of water to the biodigester and green areas. So, it is considered to have a storage tank of $1 \mathrm{~m} 3$. If the storage tank had the provisional rainwater storage range, it will be $4.12 \mathrm{~m} 3(4.50 \mathrm{~m} 3-(0.38 \mathrm{~m} 3))$, obtained from the maximum and minimum difference shown in Table 9, which would not require Let the year begin with a volume supplied by the common water supply. For safety and simplicity purposes, it would be proposed to use a tank of $4.5 \mathrm{~m} 3$ capacity

\subsection{Estimation of the maximum regulated demand for housing}

Considering that the Maximum Demand calculated is less than $10 \mathrm{KW}$, due that total house area is less that $90 \mathrm{~m}^{2}$, as shown in table 10. The single-phase or three-phase system can be used; in our case we will use the singlephase system because it is a solution to have a greater power in a single phase.

M.D $=2500 \mathrm{~W}$

$\mathrm{V}=220 \mathrm{~V}$

$\cos \phi=0.9$ since it is more resistive than inductive

$\mathrm{K}=1$, because it is a single phase

Table 10. Determination of maximum housing demand (Own source).

\begin{tabular}{|c|c|c|c|c|}
\hline \multicolumn{2}{|c|}{ DESCRIPTION } & P.I (w) & F.D $(\%)$ & M.D(w) \\
\hline \multirow{3}{*}{$\begin{array}{c}\text { LIGHTING AND } \\
\text { OUTLET }\end{array}$} & BASIC CHARGE 90M2 & 2500 & $100 \%$ & 2500 \\
\cline { 2 - 5 } & ADITIONAL CHARGE 0M2 & 0 & 0 & 0 \\
\cline { 2 - 5 } & FRACTION CHARGE 0M2 & 0 & 0 & 0 \\
\hline \multicolumn{3}{|c|}{ TOTAL (Watts) } & & 2500 \\
\hline
\end{tabular}

\section{Conclusions}

It can be concluded that rainwater supply systems are feasible in some areas where rainfall is considerable, and that their little use today is due solely to the ease of supplying through surface brake waters. The development of technologies in terms of rainwater harvesting. With the study, it is shown that these systems really work in some places where people can fully stock up with rainwater.

It is concluded that the rainwater collection system can be much more economically feasible, where water supply through the conventional surface water system is more difficult and therefore more expensive.

A very small catchment area of $50 \mathrm{~m} 2$ was used in comparison with the available area of the land of $220 \mathrm{~m} 2$, so it is concluded that there is a greater available endowment that could give a greater capacity for water saving. However, as it has a greater capacity to capture water, larger tanks and larger areas of catchment ceilings would also be needed, so a balance would have to be found that would allow for the most economical viable solution.

It can be concluded that the Bristow - Campbell method can be used to estimate global solar radiation in other areas of Peru, where there is no radiation data, but maximum and minimum daily temperatures. This result is very reliable, because said method is adapted to the geographical conditions of the country; therefore, the estimation of the global solar radiation can be made and the potential of the solar resource can be obtained.

Different wind speed samples were identified to perform the corresponding analysis, the best option being 2014 in obtaining a total of 66 data. When obtaining daily data of little variable wind speed in months and years, it can be concluded that despite obtaining little data to analyse, the result of average wind speed in the studied area is considered reliable. 


\section{References}

1. Ponce, C., García, L., Ñeco, R. (2014). Diseño de un sistema Hibrido eólico solar para suministrar de energía eléctrica a zona rural en el estado de Chihuahua. Culcyt, 54 (11). Recuperado de http://erevistas.uacj.mx/ojs/index.php/culcyt/article/v iew/865 (Consulta: 16 de mayo de 2018).

2. Camayo, B (2013). Energía Solar y Calidad Ambiental de la Región Junín. Universidad Nacional del Centro del Perú, Huancayo, Perú.

3. Baigorria, G. A., Villegas, E. B., Trebejo, I., Carlos, J. F., \& Quiroz, R. (2004). Atmospheric transmissivity: distribution and empirical estimation around the central Andes. International Journal of Climatology: A Journal of the Royal Meteorological Society, 24(9), 1121-1136.

4. Ministerio de Energías y minas (MEM). (2003). Atlas de Energía Solar del Perú, Lima, Perú.

5. Gastelo, A (2017). Estimación de la radiación solar global diaria utilizando el modelo de Hargreaves Samani. Universidad Nacional Pedro Ruiz Gallo, Lambayeque, Perú.

6. Instituto Nacional de Estadística e Informática (INEI). (2018). Censo Nacional 2017, Lima, Perú. Recuperado

de http://censos2017.inei.gob.pe/redatam/ (Consulta: 10 de Octubre de 2018)

7. SERVICIO NACIONAL DE METEOROLOGÍA E HIDROLOGÍA - SENAMHI (2003). Ministerio de
Energía y Minas. Atlas de Energía Solar del Perú. Lima, Perú.

8. Castillo, G., \& Santibanez, Q. (1981). Evaluación de la radiación solar global y luminosidad en Chile. I. Calibración de fórmulas para estimar radiación solar global diaria. Agricultura técnica.

9. Meza, F., \& Varas, E. (2000). Estimation of mean monthly solar global radiation as a function of temperature. Agricultural and Forest Meteorology, 100(2-3), 231-241

10. Barthelmie, RJ., \& Doubrawa, P. (2016). Best Practice for Measuring Wind Speeds and Turbulence Offshore through In-situ and Remote Sensing Technologies. Recuperado de http://www.geo.cornell.edu/eas/PeoplePlaces/Faculty /spryor/DoE_AIATOWEA/DoE2016Barthelmieetal BestPractice_070716-1djxj4x.pdf (Consulta: 2 de noviembre de 2018)

11. Fernández, P. (2003). Energía Eólica. Universidad de Cantabria. Recuperado de http://rsm1.redsauce.net/js/pdfjs/web/viewer.html?fil $\mathrm{e}=\mathrm{http} \% 3 \mathrm{~A} \% 2 \mathrm{~F} \% 2 \mathrm{Frsm} 1$.redsauce.net $\% 2 \mathrm{FAppCont}$ roller $\% 2$ Fcommands_RSM\%2Fapi\%2Fapi getFile.p hp\%3FitemID\%3D77\%26propertyID\%3D20\%26RS token\%3D59e8ac1045d03e2ff6564c0638315f38 (Consulta: 10 de Abril de 2018). 